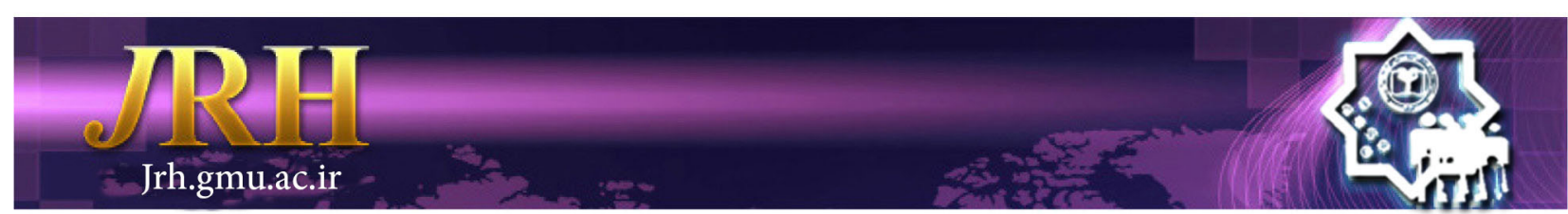

\title{
Spiritual intelligence and organizational commitment: the mediating role of psychological capital
}

Adel Zahed Babalan ${ }^{1}$, Ghaffar Karimianpour ${ }^{1}$, Mohammad Javad Ranjbar $^{2}$

\author{
Journal of Research \& Health \\ Social Development \& Health Promotion \\ Research Center \\ Vol. 8, No. 4, Jul \& Aug 2018 \\ Pages: $329-338$ \\ DOI: $10.29252 / j r h .8 .4 .329$ \\ Original Article
}

1. Department of Education, Faculty of Education and Psychology, University of Mohaghegh Ardebily, Ardebil, Iran

2. Department of Psychology, Faculty of Education and Psychology, University of Mohaghegh Ardebily, Ardebil, Iran

Correspondence to: Ghaffar Karimianpour, Department of Education, Faculty of Education and Psychology, University of Mohaghegh Ardebily, Ardebil, Iran

Email: karimiangh@gmail.com

\section{Received: 25 Feb 2016}

Accepted: 21 Sep 2016

How to cite this article: Zahed Babalan A, Karimianpour Gh, Ranjbar MJ. Spiritual intelligence and organizational commitment: the mediating role of psychological capital. $J$ Research Health2018; 8(4): 329- 338.

\begin{abstract}
Organizations need to employ committed individuals for their survival and development as well as to achieve their short- and long-term goals. In account of this, successful organizations are those with committed managers and staff. Therefore, it is important to investigate the factors influencing organizational commitment. The aim of this study was to investigate the mediating role of psychological capital in the relationship between spiritual intelligence and organizational commitment among employees of Ardabil University of medical sciences using a correlational method (structural equation modeling). Regarding the desirable size of the sample $(\mathrm{n}=125)$ for structural equation modeling, 183 employees were selected using convenience sampling method. The results showed that the direct effect of spiritual intelligence on organizational commitment and the direct effect of psychological capital on organizational commitment are statistically significant. Also, the spiritual intelligence may effect organizational commitment through psychological capital as mediator $(\mathrm{p} \leq 0.01, \beta=0.41)$.
\end{abstract}

Keywords: Commitment, Psychological, Spirituality

\section{Introduction}

Nowadays, organizational commitment is among the most significant occupational concerns as well as the most effective factors in motivation and productivity in organizations because achieving the organizational objectives and productivity depend largely on the loyalty and commitment of the staff [1]. In fact, the organizations, in order to achieve their objectives, seek to increase organizational commitment as a competitive strategy [2]. Most researchers believe that the issue of organizational commitment was introduced in the first decade of the twentieth century in the scope of organizational behavior [3]. There are various definitions of organizational commitment from different experts; Allen and Meyer have defined organizational commitment as a kind of perspective showing the rate of loyalty and interest of staff towards the organization [4,5]. Wagner describes organizational commitment as a state in which employees have adapted themselves to the organization and its objectives and tend to remain a member of the organization. Wagner 
and Helen Beck state that a true organizational commitment must make the employees loyal and attributed to their respective organization [6]. There have been proposed different models of organizational commitment one of which is the Allen and Meyer model [7]. In this model, three dimensions of organizational commitment have been introduced as follows: A) affective commitment that involves mental and emotional dependence of employees on the organization such that they are identified and introduced through the organization, B) continuance commitment that refers to the propensity to remain in the organization. This happens as a result of awareness of the consequences of leaving the organization, and C) Normative commitment that explains the beliefs and values of the people towards the advantages of remaining in the organization [8]. The committed person depends on the organization; he/she has a considerable participation in the organization and enjoys the membership of the organization. The results of different studies suggest that organizational commitment has a positive significant relationship with the related consequences such asjob satisfaction, attendance at workplace, organizational behavior, and occupational performance [9]. Therefore, organizational commitment of the employees, especially from the views of managers, is a very important factor to achieve success. Nowadays, regarding the fast changes in the structure of organizations, managers are seeking new ways to increase employees' commitment by means of which to gain competitive advantages [2]. Therefore, recognition of affecting factors in the organizational commitment can help organizations achieve their objectives. Two factors affecting organizational commitment, based on the relevant previous studies, are psychological capital and spiritual intelligence $[2,10,11]$.

The concept of spiritual intelligence in the field of organizational management was first introduced by Zohar and Marshall. They believe that spiritual intelligence by integrating intellectual intelligence and emotional intelligence facilitates the interaction between logical thinking and emotional intelligence and will lead to the increased capacity for psychological consistency [12]. Mousavi et al. have defined the spiritual intelligence as the ability to implement and develop spiritual values so that it can improve daily functioning together with physical and mental health of people [13]. Spiritual intelligence in an organization enables the employees to achieve a more integrated perspective, and thus link their business and personal life with the spiritual world. Spiritual intelligence is important at both personal and organizational levels, and by impressing people's conscience, it will create a sense of liability towards everyday responsibilities of life [14]. Many models have been represented for explaining spiritual intelligence. One of the most important models in this regard is the King's model. This model comprises 4 component: a) existential critical thinking (capacity to think critically about the nature of existence and other metaphysical subjects),

b) Personal meaning production (ability to create personal meaning and purpose in all the physical and mental experiences), c) Transcendental awareness (one's capacity to identify transcendent aspects of the self, of others, and of the physical world together with the capacity to identify the relationship of all of them with the self and the physical body), and d) Conscious State Expansion (capacity to enter and exit higher states of spirituality like pure consciousness, prayer, and meditation) [15]. Nowadays, the spiritual intelligence and its application in organizational leadership are so prevalent [16]. In the view of Vaugan, spiritual intelligence in the workplace results in the peace of mind that affects the person's efficiency, making relationships and interaction with others, management of changes, and removal of obstacles. Vaugan also believe that spiritual intelligence can positively affect work environment and it will be also effective in decision-making, problem-solving, and doing things better [17]. On the other hand, in the present challenging era, developing a special approach is essential 
towards efforts for flourishing the capacities and capabilities of human capital in order to create competitive advantages for organizations [18]. The results of various studies suggest a positive relationship between psychological capital and many desirable organizational outcomes such as job satisfaction [19], entrepreneurship of scientific board members [20], and reduction of occupational burnout [21]. The concept of positive psychological capital has roots in the works of Martin Seligman. He is known as the father of positivist psychology [22]. In fact, the psychological capital refers to the concept of "Who you are (real ego)" and "Who you wish to be (possible ego)" [23], which includes four components: A) self-efficacy (to believe in self-capabilities to mobilize motivational and cognitive resources towards successful implementation of special tasks [24], B) hope (cognitive or thinking status that enables people to recognize real but challenging objectives, and come to understand the internalized control by enough energy and will [25], C) optimism (attribution of positive events to permanent, personal, and pervasive causes and negative events to external, temporary, and specific causes [25], and d) resilience (a psychological capacity by means of which people can successfully cope with change, crisis, risk, and other challenges $[26,27]$. This new organizational approach suggests that the leaders of organizations avoid concentration on weaknesses and malfunctions of the employees and focus, instead, on their strengths and desirable qualities, increase of self-confidence, optimism, and thereby improvement of individual and organizational performance [11]. Psychological capital, with an emphasis on positive psychological variables, leads to the promotion of human capital values, enhancement of job satisfaction, increase of productivity, and improvement of organizational commitment [28]. Many studies have been conducted with respect to these three variables. Hoveida et al. in their study entitled "the relationship between psychological capital and organizational commitment components" came to the conclusion that hope and selfefficacy could be significant predictors of continuance and affective commitment and the point that optimism, self-efficacy, and resilience could significantly predict normative commitment [11]. Hariri and Zarrinabadi in their study entitled

"evaluation of the relationship between spiritual intelligence and occupational commitment in the librarians of Isfahan Public Universities" concluded that there is a significant relationship between the components of spiritual intelligence and occupational commitment among librarians [29]. Ghorbani et al., in their study entitled "the relationship between spiritual intelligence and organizational commitment in a governmental organization" concluded that there is a significant relationship between spiritual intelligence and its components on one hand and organizational commitment on the other hand and also the point that spiritual intelligence has the highest correlation with emotional organizational commitment [30]. Ghahramani et al., in their study entitled "investigation of the relationship between managers' spiritual intelligence and employees' commitment in Pipeline and Telecommunication Company of Iran" concluded that managers' spiritual intelligence has a positive significant effect on employees' commitment. Likewise, all of the four components of managers' spiritual intelligence, and most especially existential thinking and personal meaning, have had a significant effect on employees' commitment [2].ZabihiandSagharvani,intheirstudyentitled "spiritual intelligence and organizational commitment" concluded that spiritual intelligence could be a significant positive predictor of organizational commitment and its dimensions [14]. Shahnavaz and Jafari, in a study entitled "psychological capital as a predictor of organizational commitment and organizational citizenship behavior", concluded that there is a direct, significant relationship between psychological capital and organizational commitment [31]. Luthans, Norman, Olive, and Avi, in their study entitled "The mediating role of psychological 
capital in the supportive organizational climate- employee performance relationship", concluded that there is a significant relationship between the dimensions of psychological capital and employees' performance [23]. Luthans and Joseph came to the conclusion that organizational commitment has a correlation with the dimensions of psychological capital [18]. Simon and Buitendach, in their study entitled "investigation of the psychological capital, occupational enthusiasm, and organizational commitment among employees of South African Telecommunication Company", concluded that there is a significant, positive correlation between psychological capital and organizational commitment [32]. Research has shown that employees who are committed to their organizations have much better performance; they rarely leave their job, have a greater incentive, and have more agreement and adaptability with the organization [19]. Literature of the organizational commitment indicates that this variable is a sub function of personal characteristics and situational factors associated with the workplace [11]. Thus, organizations, through recognition of commitment rate among their employees and its affecting factors, will be able to realize their objectives [19]. With respect to the significant role of organizational commitment and its effective factors in the performance of organizations, in this study, the relationship between spiritual intelligence and organizational commitment regarding the mediating role of psychological capital was investigated. The following hypotheses were tested:

- Spiritual intelligence has a direct effect on organizational commitment.

- Psychological capital has a direct effect on organizational commitment.

- Spiritual intelligence has a direct effect on organizational commitment through psychological capital as a mediator.

- The conceptual model of this study is as follows:

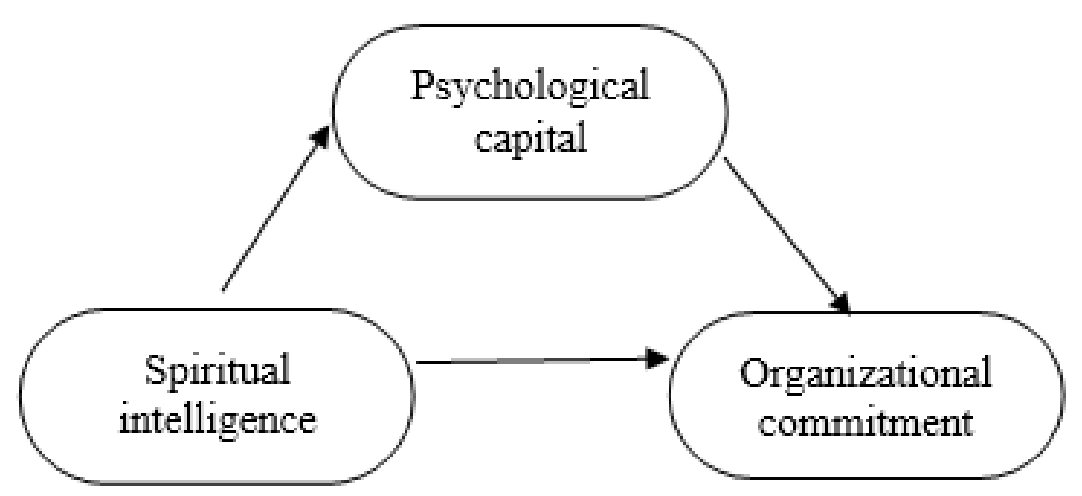

Figure 1 The conceptual model of the study

\section{Method}

This correlational research was conducted using structural equation modeling. The statistical population included all employees of Ardabil University of Medical Sciences $(\mathrm{N}=300)$ whom from 183 participants were selected as statistical sample using convenience sampling method. Muller has introduced a ratio of sample size to free parameter of the model in order to determine the sample size in structural equation modeling [34]. He determines this ratio at least 5 to 1 . With regard to the 25 free parameters in the model, a sample of 125 participants $(25 *$ 5 ) seems to be favorable. Har et al., for models with maximum 5 structures and minimum 3 indices for each indigenous structure, agree about a sample size equal to 100 as favorable. According to the normality of the variables of the model and the high rate of overlap among them, it was attempted to select a sample consisting of individuals more than required (sample size of the present study included 183 participants). The gathered data were 
analyzed using by Amos Software Version 22. King's scale of spiritual intelligence selfassessment was used for data collection. The scale is an instrument including 24 questions in 4 subscales of existential thinking (questions 1 , $3,5,9,13,17,21)$, personal meaning production (questions $7,11,15,19,23$ ), consciousness state expansion (questions 2, 6, 10, 14, 18, 20, 22) and transcendental awareness (questions $4,8,12,16,24)$. The rating system is based on a 5-point Likert scale. The validity of the questionnaire was approved by five professors of Mohaghegh Ardabili University and the reliability was determined as 0.89 using Cronbach's alpha, which is in accordance with the value reported by Moallemi et al. [35]. To collect data on organizational commitment, Allen and Meyer's organizational commitment questionnaire was used. This questionnaire is composed of 24 questions in 3 dimensions of affective commitment (questions 1 to 8 ), continuance commitment (questions 9 to 16), and normative commitment (questions 17 to 24). This questionnaire is scored based on a 5-point Likert scale from strongly disagree (1) to strongly agree (5). The validity of the questionnaire was approved by five professors of Mohaghegh Ardabili University and the reliability was determined as 0.86 using Cronbach's alpha; the reliability of this questionnaire has been reported to be 0.73 by Rezaeian and keshtegar [36]. To measure psychological capital, psychological capital questionnaire of Luthans et al [18]. was used.
This questionnaire has 24 questions in 4 subscales of self-confidence/ self-efficacy (questions 1 to 6), hope (questions 7 to 12), optimism (questions 13 to 18), and flexibility / resilience (questions 19 to 24). The participants respond to the questions based on a 6-point Likert scale (from strongly disagree to strongly agree). Luthans et al. have reported the validity of the questionnaire above 0.90 . After translation in Persian and revision, the validity was approved by 5 expert professors. Also, the reliability of the questionnaire has been reported by Hoveida et al. to be 0.77 using Cronbach's alpha coefficient [11]. In this study, the content validity of the questionnaire was approved by five professors of the department of educational sciences and its reliability was obtained as 0.84 using Cronbach's alpha.

\section{Results}

162 out of 183 individuals participated in this study were male (\%88.5) and $21(\% 12.2)$ were female. In terms of age, 20 participants were between 25 and 30 years old (\%13.66), 155 between 30 and 45 years old (\%84.69), and 5 participants between 45 and 50 years old (\%2.73). In terms of academic degree, 22 persons had Associate's degree (\%12.01), 140 Bachelor's degree (\%76.44), and 18 Master's degree (\%9.82).

Table 1 shows indices of mean, standard deviation, and correlation coefficients between the variables.

Table 1 Indices of mean, standard deviation, and correlation coefficients between the variables of
the study
\begin{tabular}{lccccc}
\hline M & SD & 1 & 2 & 3 \\
\hline 1. Spiritual intelligence & 68.6 & 14.2 & 1 & & \\
2. Psychological capital & 53.46 & 13.23 & $0.43^{* *}$ & 1 & \\
3. Organizational commitment & 56.30 & 12.82 & $0.37^{* *}$ & $0.32^{* *}$ & 1 \\
\hline
\end{tabular}

To test the structural model of the relationship between spiritual intelligence and organizational commitment with regard to the mediating role of psychological capital structure, the related items in the questionnaires were used as indicators of indigenous variables. After drawing cause and effect pathways among indigenous variables, the analysis was performed and statistical features of the model were examined with regard to the model coefficients, significance levels, and fit indicators. Figure 2 shows the pathways coefficients of the model explaining organizational commitment. 


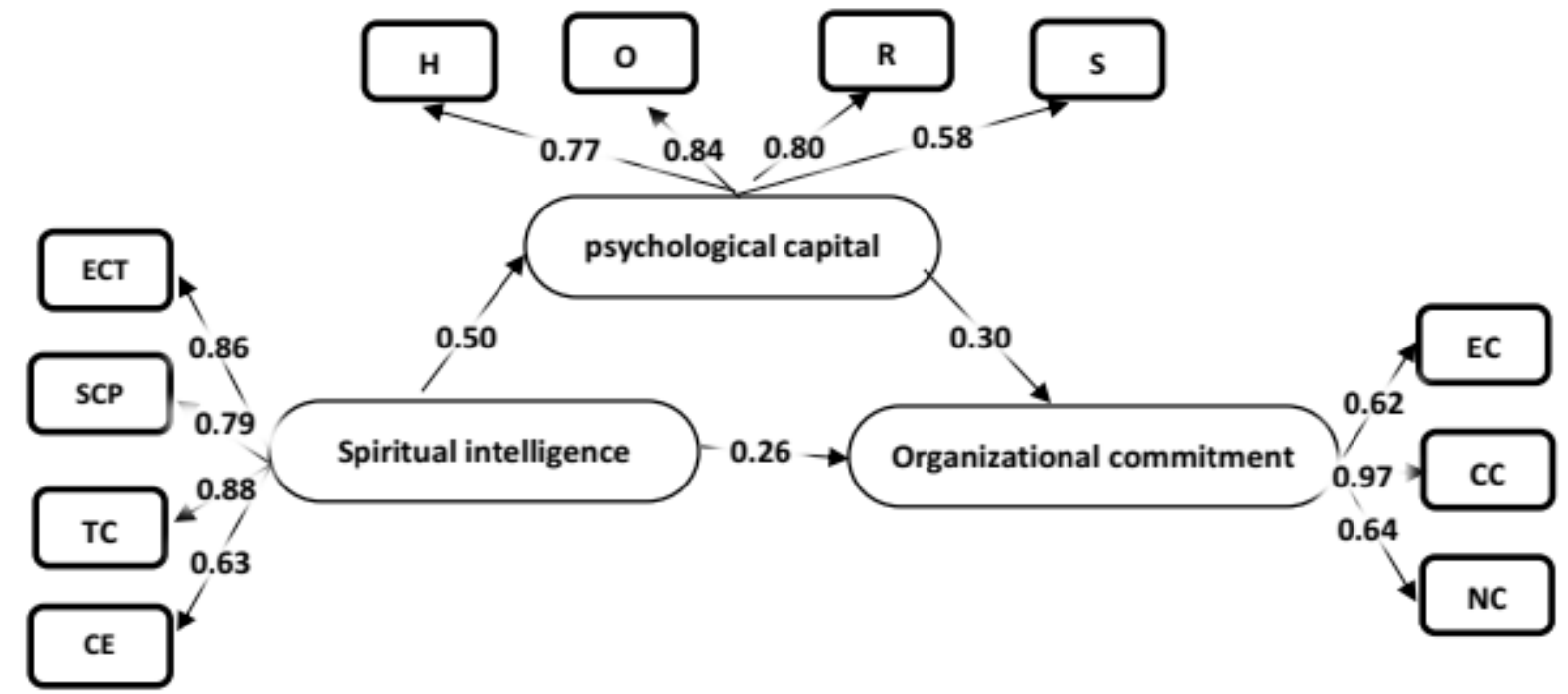

Figure 2 Standard coefficients of the indigenous structures model and observed variables (Amos output)

Abbreviations used in the diagram: spiritual intelligence dimensions (E.C.T $=$ Existential Critical Thinking; S.C.P = personal meaning production; T.C $=$ transcendental awareness; C.E $=$ Consciousness state Expansion); psychological capital dimensions $(\mathrm{H}=$ hope; $\mathrm{O}=$ Optimism; $\mathrm{R}=$ Resilience; $\mathrm{S} . \mathrm{E}=$ Selfefficacy); Organizational commitment dimensions (Affective Commitment= E.C; C.C $=$ continuance Commitment; N.C $=$ Normative Commitment). As shown in Figure 2, paths of spiritual intelligence to psychological capital $(p<0.01, \quad \beta=0.50), \quad$ spiritual intelligence to organizational commitment $(\mathrm{p}<0.05$, $\beta=0.26$ ), and finally psychological capital to organizational commitment $(\mathrm{p}<0.01$, $\beta=0.30$ ) were statistically significant. These coefficients represent the direct relations between the variables of the study. Indirect effects, total effect of the model, and relevant statistical indices also have been summarized in Table 2.

Table 2 Direct indirect, and total effects of indigenous variables of the model (Amos output)

\begin{tabular}{lccccccccc}
\hline \multirow{2}{*}{ From } & \multicolumn{4}{c}{ To: organizational commitment } & \multicolumn{3}{c}{ To: psychological capital } \\
\cline { 2 - 10 } & \multicolumn{3}{c}{ Spiritual intelligence } & \multicolumn{2}{c}{ Psychological capital } & \multicolumn{2}{c}{ Spiritual intelligence } \\
\hline \multirow{2}{*}{ Direct effect } & 0.26 & 0.11 & 0.024 & 0.30 & 0.1 & 0.006 & 0.50 & 0.08 & 0.000 \\
Indirect effect & 0.15 & 0.06 & 0.004 & - & - & - & - & - & - \\
Total effect & 0.41 & 0.09 & 0.000 & 0.30 & 0.1 & 0.006 & 0.50 & 0.08 & 0.000 \\
\hline
\end{tabular}

Statistical indices related to direct, indirect, and total effects of the model have been summarized in Table 2. The total effect of spiritual intelligence on organizational commitment, in other words, the sum of the direct and indirect effect of spiritual intelligence on organizational commitment regarding the mediating role of psychological capital is statistically significant $(p<0.01, \beta=0.41)$. In the structural equation modeling, after determining the coefficients of paths and different effects in the model, in order to evaluate the fit of the model, some statistics are provided by the software. These statistics examine the consistency rate between observed covariance matrix and estimated covariance matrix. In Table 3, the indices of the fit of the model have been reported.

As summarized in Table 3, goodness of fit index (GFI), Tucker and Lewis index (TLI), and incremental fit index (IFI) all are above 0.9 . The ratio of Chi-square to degrees of freedom $\left(\mathrm{X}^{2} /\right.$ df) equals to $1 / 2$ that is at an acceptable level. The root mean square error of approximation (RMSEA) index equals to 0.04 . It should be 
noted that in a perfect fit, this value equals to zero although the values less than 0.08 are good enough. However, for values higher than 0.1 , there is an obligation to reject the model. Thus, the present model is quite favorable in terms of RMSEA index. Among the nine examined indices, all of them are favorable. Therefore, it can be said that all values related to the comparative indices of the model indicate the proper fit of the structural model for prediction of organizational commitment through psychological capital and spiritual intelligence.

\begin{tabular}{lccl}
\multicolumn{4}{l}{ Table 3 Fit indices of the model (Amos output) } \\
\hline \multicolumn{1}{l}{ Model fit } & Value & Ideal values & \\
\hline $\mathrm{X}^{2}$ & 49.14 & $>0.50$ & Favorable \\
$\mathrm{Df}$ & 14 & - & Favorable \\
$\mathrm{X}^{2} / \mathrm{df}$ & 1.2 & $<3$ & Favorable \\
$\mathrm{RMSEA}$ & 0.04 & $<0.08$ & Favorable \\
GFI & 0.933 & $>0.90$ & Favorable \\
AGFI & 0.89 & $>0.90$ & Favorable \\
TLI & 0.98 & $>0.90$ & Favorable \\
CFI & 0.98 & $>0.90$ & Favorable \\
IFI & 0.98 & $>0.90$ & Favorable \\
\hline
\end{tabular}

\section{Discussion}

Efficiency and development of any organization depend on the proper management of human resources. In today's competitive environment, one of the valuable resources of organizations is committed, satisfied employees who are attempting to achieve organizational objectives with power and enthusiasm. This study was carried out aiming at investigation of the relationship between spiritual intelligence and organizational commitment regarding the mediating role of psychological capital. The average scores of spiritual intelligence of the employees were 68.6, psychological capital 53.46, and organizational commitment 56.3. The results of data analysis in order to test the first hypothesis indicated that spiritual intelligence has a direct, significant effect on organizational commitment $(\beta=0.26)$. This result is in accordance with the findings of Hariri and Zarrinabadi [29], Ghorbani et al. [30], Ghahramani et al. [2], and Zabihi and Sagharvani [14].

Research in the field of organizational behavior indicates that people come to the occupation with something more than their body, mind, and emotions; they bring their personal talent and unique spirit into the work; something that can be called spirituality and spiritual intelligence [36]. Nowadays, spiritual intelligence is in the focus of attention more than ever due to the downfall of core values. High spiritual intelligence in the occupational environment has been associated with the increase of creativity, honesty, confidence, and commitment [13]. Accordingly, the leaders of organizations attempt to provide spiritual landscape for the organizations through institutionalization of spirituality [37]. On the other hand, nowadays, it is generally believed that committed employees are more valuable than other employees. In other words, organizational commitment, as an outlook on employees' loyalty to the organization, is an ongoing process through which members of organization exhibit their interest towards the organization and its continuous success and efficiency. A variety of factors are determinant in the promotion of organizational commitment. The results of this study showed that spiritual intelligence is one of those factors. People with high spiritual intelligence will make a kind of conformity between personal beliefs and values and occupational ones. They believe that they are engaged in an important, meaningful work. This will create a significant motivation for them and make them committed towards the objectives of the organization. In fact, people with high spiritual intelligence can show a better performance and exhibit higher commitment 
and liability. Hence, encouraging spirituality at workplace, especially in the environments in which employees face daily routine tasks, can lead to increased creativity, honesty, and trust, and a sense of personal development, organizational commitment, job satisfaction, job involvement, and so on will be created [10]. With regards to the above mentioned materials, by applying and strengthening spiritual intelligence, steps might be taken towards more empowerment of employees as well as enhancement of their commitment to the organization, resulting in their more and more attempts to achieve personal and organizational objectives.

Data analysis in order to test the second hypothesis showed that psychological capital has a direct, significant effect on organizational commitment $(\mathrm{b}=0.30)$, which is in accordance with the results of Hoyeda et al. [11], Shahnawaz and Jeffrey [31], Luthans et al. [23], Luthans and Joseph [18], and Simon and Buitendach [32]. In order to explain the significant relationship between psychological capital and organizational commitment, the dimensions of psychological capital and the effect of each dimension on the organizational performance can be referred to. The first dimension is selfefficacy. This implies that when employees trust their abilities and talents in fulfilling their assignments, they will be provided with higher motivation towards occupational success, which in turn leads to an effective and positive presence in the organization. On the other hand, hope as another dimension will enable the individuals to determine the real but challenging objectives and move towards those objectives with enough will and energy. This, in long-term, would increase their commitment towards the organization.

Optimism is another dimension of psychological capital which refers to a positive outlook on the expected results. Optimistic people in an organization associate their successes with internal factors and their failures with external ones. Optimism towards the expected results would increase the individuals' commitment towards the organization. Resilience as the fourth dimension of psychological capital is the capacity of rehabilitation against difficulties.
It will make individuals adaptive in front of difficult situations, which in turn leads a person to be more committed to the organization.

The third hypothesis, spiritual intelligence, has an indirect effect on organizational commitment through psychological capital.

The analysis of results showed that spiritual intelligencehasanindirecteffectonemployees' commitment through psychological capital (b $=0.41$ ). Regarding this indirect effect, it can be said that those who act within a spiritual framework, experience more comfort, dynamism, and flexibility. In other words, strengthening spiritual foundations especially the religious ones would lead to enrichment of employees' psychological capital. Accordingly, enhancement of different dimensions of psychological capital such as employees' self-efficacy, self-confidence, hope, and resilience would increase the commitment of the employees in universities towards their duties and assignments.

Using the questionnaire and not using other tools in collecting data and limiting the generalizability of data to employees of other universities is one of the limitations of this research.

\section{Conclusion}

Nowadays, organizational commitment and its positive consequences are known in all organizations. On the other hand, the negative consequences of the lack of organizational commitment in employees have been also determined. Accordingly, considering the significance of organizational commitment of the employees as well as the results of the present study, which indicated a positive relationship between spiritual intelligence and organizational commitment, it is recommended for managers to pave the ground for training spiritual intelligence as well as psychological capital in order to enable their employees to reach the expected objectives and increase their job satisfaction and organizational commitment. Acknowledgment: the authors would announce their utmost thanks and appreciation towards the employees of Ardabil University of 
Medical Sciences who carefully responded to the questionnaires.

\section{Acknowledgment:}

Thank for all the staff members who participated in the event

\section{Contribution}

Study design: AZ

Data collection: GHK, MJR

Data analysis: GHk, MJR

Manuscript preparation: AZ, GHk, MJR

\section{Conflict of Interest}

"The authors declare that they have no competing interests."

\section{Funding}

The authors received no financial support for this research.

\section{References}

1- Abdollahi B, Yousliani GA, Hatamian J. Investigation of the relationship between organizational justice and organizational commitment in teachers of elementary schools. Journal of New Thoughts on Education2014; 10(2): 92-118.

2- Ghahramani S, Adnanrad A, Ebrahimi R. Spiritual intelligence and employee engagement of Iranian pipeline and telecommunication of oil company. Human Resource Studies2015; 2(5): 43-50.

3- Buck JM, Watson JL. Retaining staff employees: The relationship between human resources management strategies and organizational commitment. Innovative Higher Education. 2002; 26(3): 175-93.

4- Miller K. Values, attitudes and job satisfaction. In: Robbins SP, Odendaal A, Roodt G, eds. Organisational behaviour: global and southern African perspectives. Cape Town: Pearson education South Africa; 2003.

5- Masrek MN, Osman MAF, Ibrahim Z, Mansor AN. Malaysian computer professional: assessment of emotional intelligence and organizational commitment. Procedia Soc Behav Sci2015;172: 238-45.

6- Wagner 111 JA, Hollenbeck JR. Organizational behavior: securing competitive advantage. Routledge; 2014.

7- Allen NJ, Meyer JP. The measurement and antecedents of affective, continuance and normative commitment to the organization. J Occup Organ Psychol1990; 63(1): 1-18.

8- Zareei M. Advanced organizational behavior management. Tehran: Agah; 2015.

9- Shiuan CB, DYn I, Relley JH. Organizational commitment: the Chinese super visionary commitment and employee outcomes in context proximal hypothesis or global hypothesis. J Organ Behav2003; 24(3): 14-45.

10- Golparvar M, Jafari M, Javadian Z. Prediction of psychological capital through components of spirituality among Nurses. Iranian Journal of Psychiatic Nursing. 2013; 1(3): 35-44.

1- Kalantarkousheh SM, Sharghi N, Soleimani M, Ramezani S. The role of spiritual intelligence on organizational commitment in employees of universities in Tehran province, Iran. Social and Behavioral Sciences 2014; 140: 499-505.

12- Cavanagh GF. Spirituality for managers: context and critique. Journal of Organizational Change Management 1999; 12(3): 186-99.

13- Mousavi S, Talebzadeh Nobarian M, Moorkani G. Relationship between spiritual intelligence and organizational citizenship behavior of secondary school teachers in the city of Zanjan. Journal of Educational Psychology2011; 7(22): 65-94.

14- Zabihi MR, Saghravani S. Spiritual intelligence and organizational commitment. Journal of Government Management Perspective2011; 2(2): 18-25.

15- King DB. Rethinking claims of spiritual intelligence: a definition, model, and measure. Ann Arbor, Michigan, USA: ProQuest; 2008.

16- Amram, Yosi (2009). The contribution of emotional and spiritual intelligences to effective business leadership. [dissertation]. Palo Alto, CA: Institute of Transpersonal Psychology; 2009.

17- Vaugan F. What is spiritual intelligence. J Humanist Psychol2003; 42(2): 16-33.

18- Luthans F, Youssef CM, Avolio BJ. Psychological capital: developing the human competitive edge. Oxford: Oxford University Press; 2007.

19- Esfahany MN, Esfahany AN, Noori A. The relationship between servant leadership and organizational commitment and its components in staff welfare organization of Isfahan. J Public Manag2011; 4(11): 45-54.

20- Forouhar M, Hovaida M, Jamshidian A. Explain the relationship between psychological capital and entrepreneurship faculty members. Journal of Counseling and Psychotherapy Culture2011; 8(2): 83-98.

21- Alipour A, Saffari Nia M, Sarami Forushani G, Agha Alikhani A, Akhundi N. Evaluation of the effectiveness of psychological capital intervention of Luthans on job burnout in the experts working in Iran Khodro Diesel Company. Occupational Medicine Quarterly Journal2013; 5(3): 30-41.

22- Seligman ME. Learned optimism: how to change your mind and your life. New York City: Vintage; 2011.

23- Luthans F, Norman S, Avolio B, Avey J. The mediating role of psychological capital in the supportive 
organizational climate- employee performance relationship. Journal of Organizational Behavior2008; 29: 219-38.

24- Bandura A. Self-efficacy: toward a unifying theory of behavioral change. Psychol Rev1977; 84(2): 191.

25- Snyder CR. Hope theory: Rainbows of the mind. Psychological Inquiry2002; 13: 249-75.

26- Stewart M, Reid G, Mangham C. Fostering children's resilience. J Pediatr Nurs 1997; 12(1): 21-31.

27- Masten AS, Reed MG. Resilience in development. In: CR Snyder, SJ López, eds. Handbook of positive psychology. New York: Oxford University Press; 2002. pp: 74-88.

28- Wegge J, Schmidt KH, Parkes C, Dick R. Taking a sickie: Job satisfaction and job involvement as interactive predictors of absenteeism in a public organization. J Occup Organ Psychol2007; 80(1): 77-89.

29- Hariri N, Zarrinabai Z. Assess the relationship between spiritual intelligence and employee engagement in librarians of Isfahan public universities. Journal of Studies on Library \& Information Science, University of Chamran Martyr2011; 19(10): 79-96.

30- Ghorbani M, Haghighi M, Tajrishi MA, Rastemighadam A. Relationship between spiritual intelligence and organizational commitment in a government agency. Journal of Management Process
Development $2011 ; 25(3): 43-50$.

31- Shahnawaz M, Jafri MH. Psychological capital as predictors of organizational commitment and organizational citizenship behaviour. Journal of the Indian Academy of Applied Psychology2009; 35: 78-84.

32- Simons JC, Buitendach JH. Psychological capital, work engagement and organisational commitment amongst call centre employees in South Africa. $S A$ Journal of Industrial Psychology2013; 39(2): 1-12.

33- Hodges TD. An experimental study of the impact of psychological capital on performance, engagement, and the contagion effect. [Dissertations]. College of Business Administration 2010. pp: 7.

34- Muller Ro. Basic princilpes modeling. NY: springer; 1996.

35- Moalemmi S, Bakhshani NM, Raghibiy M. The relationship between mental health, spiritual intelligence and thoughts in the Sistan-Baluchestan university student. Fundamentals of Mental Health2011; 12(3): 702-9.

36- Rezaeian A, Keshtegar A. The relationship between emotional intelligence and organizational commitment. Journal of Management Message2008; 5(3): 27-39.

37- Sagharavany S. The spiritual intelligence for the individual and the organization. Journal of Tadbier 2007 : 21(215): $110-9$.

Copyright(C) 2016 ASP Ins. This open-access article is published under the terms of the Creative Commons Attribution-NonCommercial 4.0 International License which permits Share (copy and redistribute the material in any medium or format) and Adapt (remix, transform, and build upon the material) under the Attribution-NonCommercial terms. 